\title{
A dispersão da "chama pentecostal" na seara batista em meados das décadas de 1950 e 1960 - notas históricas sobre a formação da ala carismática batista brasileira
}

The dispersion of the "pentecostal flame" in the Baptist field in the mid-1950 and 1960s

- historical notes on the formation of the Brazilian Baptist charismatic setor

Thiago Moreira*

\begin{abstract}
Resumo
A presente comunicação é fruto de pesquisa histórica sobre o curso da manifestação ou irrupção do movimento carismático no protestantismo brasileiro, mais especificamente, nas igrejas batistas e pretende mostrar a formação do que futuramente se convencionou chamar de protestantismo renovado. Para tanto, nos valemos de fatos ocorridos no final da década de 1950, bem como ao longo da década de 1960, com as tensões e rupturas institucionais provocadas pelo encontro entre as experiências protestante e pentecostal.
\end{abstract}

Palavras chaves: Renovação Espiritual; Pentecostalismo; Igreja Batista da Lagoinha.

\begin{abstract}
This communication is the fruit of historical research on the course of the manifestation or irruption of the charismatic movement in Brazilian Protestantism, more specifically in the Baptist churches and intends to show the formation of what in the future has been called the renewed Protestantism. To do so, we use facts that occurred in the late 1950's, as well as trough out the $1960 \mathrm{~s}$, with the institutional tensions and ruptures provoked by the encounter between the protestant and pentecostal experiences.
\end{abstract}

Abstract: Spiritual Renewal; Pentecostalism; Igreja Batista da Lagoinha.

Comunicação submetida em 16 de janeiro de 2017 e aprovada em 17 de março de 2017.

* Doutorando e mestre em Ciência da Religião pela Universidade Federal de Juiz de Fora. País de Origem: Brasil. E-mail: thiago_moreira83@yahoo.com.br. 


\section{Introdução}

O caráter multifacetado do campo religioso brasileiro já é conhecido dos estudiosos da Religião. Diversos congressos e conferências são dedicados ao debate acerca das diversas formas através das quais o homem se apropria da relação com o sagrado, com suas simbologias e significados; seus sentidos e apropriações em planos "seculares e profanos"; seus "rituais e narrativas" e o rico caráter que se desvela mostrando, também, ambiguidades e idiossincrasias.

Os que voltam seus olhares para a tradição cristã, mais especificamente para a ramificação que advém da Reforma Protestante podem ter uma compreensão rígida sobre o que viria a ser o protestantismo e o pentecostalismo. Este se basearia em uma experiência carismática de efervescência espiritual, "quente"; enquanto aquele teria uma experiência religiosa mais pautada em uma "mística letrada", algo mais "frio".

Não obstante tal quadro servir para alguns fins didáticos e nos dar subsídios para iniciar pesquisas sobre o tema, não devemos esquecer que existem algumas arestas que não se permitiram aparar nestes quadros. Assim, surgiram protestantismos, (neo)pentecostalismos com convergências e divergências, formação de ortodoxias, fundamentalismos, heresias, liberalismos. Nesta comunicação tem-se o objetivo de mostrar como as igrejas batistas das décadas de 1950 e 1960 se relacionaram com a experiência pentecostal e como daí resultou o que se convencionou chamar protestantismo renovado.

O Movimento de Renovação Espiritual que será abordado a seguir, e que propagou a experiência carismática em muitas igrejas protestantes brasileiras, teve papel fundamental na formação de diversas igrejas evangélicas, como, por exemplo, a Igreja Batista da Lagoinha (Belo Horizonte, MG). Tal movimento merece detalhamentos e olhares dos pesquisadores da Ciência da religião e áreas 
afins para melhor compreensão da dinâmica do campo religioso evangélico brasileiro. ${ }^{1}$

\section{Movimento carismático no protestantismo brasileiro}

O surgimento de estruturas teológicas diversas, e até mesmo divergentes nas igrejas protestantes não recebeu um tratamento uniforme. Há igrejas em que esta nova articulação da fé não se apresentou como um perigo concreto; enquanto que, em outras, as novas articulações ameaçaram a ortodoxia, o domínio do discurso teológico tradicional. Como aponta Rubem Alves (1979, p. 29), em alguns casos certas igrejas não viram a uniformidade doutrinária como essencial à unidade da comunidade; para outras, por sua vez, a unidade doutrinária se constitui na marca fundamental de identidade.

O advento desta expansão pentecostal, ou melhor, da experiência pentecostal em meio às igrejas protestantes tradicionais, trouxe à baila novas formas de experienciar sua religiosidade que para uns seria uma forma mais livre, emocional e viva, para outros, uma forma herética, irracional e infantil. Assim, a questão do batismo no Espírito Santo e as possíveis manifestações que lhe seriam características apresentaram-se como um desafio teológico e institucional - o que se deu, no caso deste estudo, com as igrejas batistas.

Com o intuito de proporcionar um "novo fôlego" à experiência religiosa protestante, especialmente nas décadas de 1950 e 1960, a experiência pentecostal adentrou as portas do protestantismo tradicional histórico como uma possibilidade de se (re)apropriar de uma espiritualidade originária do protocristianismo.

A atitude inicial foi acolhedora, já que o próprio corpo protestante tradicional já se empenhara em ver suas fileiras acrescidas de um dinamismo

\footnotetext{
${ }^{1} \mathrm{O}$ texto desta comunicação traz reflexões a partir da pesquisa histórica que subsidiou a elaboração de minha dissertação de mestrado defendida no Programa de Pós-graduação em Ciência da Religião da UFJF em 2016. (MOREIRA, 2016). A pesquisa compila eventos e pessoas que seriam de grande relevância para a formação do movimento carismático protestante no Brasil.
} 
evangelístico, expansionista e que proporcionasse uma elevação da experiência religiosa e do fervor religioso.

Podemos vislumbrar, neste mesmo período, o início de campanhas de avivamento espiritual e cura divina promovidas pelos pastores e evangelistas “avivalistas” que por vezes eram recebidos em igrejas tradicionais. Tal recepção foi o prenúncio de um movimento interdenominacional chamado de "Cruzada Nacional de Evangelização" (e que mais tarde constituiria a Igreja do Evangelho Quadrangular). Diversas igrejas do protestantismo histórico abriram suas portas para estas campanhas e até mesmo as incentivavam (CAMPOS, 2011, p. 511), já que iam ao encontro de suas expectativas de crescimento e não feriam, em princípio, seus preceitos teológicos e doutrinários. Entretanto, devemos lembrar o exemplo do setor batista que já havia passado por uma experiência conflituosa quando da passagem dos missionários suecos, Gunnar Vingren e Daniel Berg, em solo brasileiro, no início do século XX (1911), originando, após, as Assembleias de Deus, causando certo estranhamento frente a certos cultos mais avivalistas.

Ao mesmo passo em que o propósito evangelístico estava sendo atingido com o alcance do crescimento numérico de visitantes nos cultos, as manifestações mais efusivas, características dos cultos pentecostais, começaram a ser alvo de debate interno dentro das igrejas tradicionais, o que, mais tarde, seria motivo de cismas institucionais em algumas ocasiões.

Desta feita, não mais promovendo estas campanhas de evangelização, cura e avivamento nestes moldes, as igrejas tradicionais fecharam suas portas fazendo com que os pregadores avivalistas e de cura divina passassem a realizar seus encontros em tendas de lona trazidas dos EUA, motivo pelo qual ficaram apelidados de "Cultos das Tendas" (CAMPOS, 2011, p. 511); posteriormente viriam a compor o que Paul Freston (1994) chamou de "segunda onda" do pentecostalismo. 
Sobre a relação não muito harmônica que estava se desenvolvendo nos setores batistas em relação à experiência carismática, bem como as campanhas de avivamento e cura divina, podemos colher excertos de matérias jornalísticas de publicações no periódico oficial da denominação, O Jornal Batista, podendo-se citar o texto de José F. de Mendonça (1959) intitulado "Curas Divinas ou Tendas das Curas Divinas”. No texto, o autor traça críticas a Manoel de Melo que deu origem ao "Movimento Brasil para Cristo". Dentre as críticas ventiladas no referido artigo, José F. de Mendonça acusa tal movimento das "tendas de cura divina" de não ser evangélico ou protestante, haja vista que tinha claras conotações pentecostais. Diz o autor:

um novo movimento que se iniciou em São Paulo em 1952 e tem com pioneiro o missionário pernambucano, Manuel de Melo, último dos 21 filhos dados à luz por uma piedosa Mãe que, apesar de tão experimentada em por gente no mundo, havia sido terminantemente proibida pelo médico de ter mais um rebento. Por esse motivo, Manuel de Melo se considera um novo Messias, familiarizado com Billy Graham, consciente de sua obra a ser realizada, a qual deu o nome de: "Movimento Brasil para Cristo". No Teatro de Alumínio, pagando cinco mil cruzeiros por uma noite de segunda-feira, Manuel começou a promover sermões públicos, sempre baseados no "Vinde para serdes curados". Uma verdade que precisa ser dita bem alto é a de que esse movimento não é protestante nem evangélico, pois que é secundado pelo pentecostalismo, em cujos templos o sr. Manuel de Melo se pontifica e realiza seus milagres de cura divina. (MENDONÇA, J. F., 1959).

As denominações protestantes passaram a tratar o tema do pentecostalismo com tons mais críticos, inclusive publicando diversos artigos em seus respectivos periódicos, demonstrando, em suas concepções, os eventuais desvios teológicos perpetrados pelos pentecostais e os danos que isto poderia causar à igreja e a uma espiritualidade saudável. Esta atitude mais direta no tratamento da questão pentecostal no seio destas denominações não impediu a debandada de certo número de seus adeptos em busca de outra forma de espiritualidade. 


\section{0 caso batista: Renovação Espiritual}

Para melhor compreendermos como se deu o processo histórico de carismatização das igrejas protestantes brasileiras, é proveitoso que debrucemos por alguns momentos em alguns aspectos biográficos de figuras que foram, dentre outras, cruciais para a propagação deste movimento dos carismas. Neste sentido, damos destaque a três pessoas em especial, Rosalee Mills Appleby (1895-1991), missionária norte-americana enviada ao Brasil juntamente com seu esposo; Enéas Tognini (1914-2015) e José Rego do Nascimento (1922-2016), pastores batistas de igrejas tradicionais até o momento de cisão institucional, quando se tornaram membros da igreja batista nacional (advindos do Movimento de Renovação Espiritual).

Rosalee Mills Appleby e seu esposo, o também missionário batista norteamericano David Percy Appleby, chegam ao Brasil em 1924 e fazem planos para este seu campo missionário. Para tanto, conseguem auxílio financeiro da Primeira Igreja Batista de Tulsa e da Primeira Igreja Batista de Springfield. Contudo, um ano após a chegada do casal em terras brasileiras (primeiramente no Rio de Janeiro e depois em Belo Horizonte), Rosalee perde seu esposo e dá a luz ao filho do casal, dando-lhe o nome de David em sua homenagem. (XAVIER, 1997).

Com a perda de seu esposo e a continuidade de seu trabalho missionário, Rosalee inicia seus trabalhos no Colégio Batista Mineiro, lecionando para crianças e escrevendo folhetos e livros com cunho devocional e com uma tonalidade mais pautada na busca por uma vida mais devotada de comunhão divina. A produção bibliográfica de Rosalee é grande. Destacam-se os chamados "Folhetos de Vida Vitoriosa" que eram enviados a pastores e missionários em todo o Brasil e que tiveram papel fundamental na veiculação da mensagem avivalista.

Um dos pastores que compartilhava em boa medida do propósito de Rosalee foi José Rêgo do Nascimento que, ainda enquanto pastor batista de uma igreja tradicional (Igreja Batista de Vitória da Conquista), confessou algum tempo depois 
ter passado pela experiência denominada “batismo pelo Espírito Santo” em 1955 (XAVIER, 1997, p. 54). O reconhecimento de José Rêgo enquanto pregador pautado por busca mais avivalista de experiência espiritual levou-o a ser convidado para pastorear uma recém-formada igreja batista em Belo Horizonte em dezembro de 1957 e que viria a se tornar a Igreja Batista da Lagoinha.

A vinda de José Rêgo a Belo Horizonte facilitou seu contato com Rosalee, o que em certa medida foi benéfico para a expansão das premissas carismáticas no seio protestante. Enquanto pastoreava a Igreja Batista da Lagoinha e pregava em diversas igrejas sobre o avivamento espiritual, José Rêgo ainda possuía um programa de rádio batizado, por sugestão de Rosalee, de Renovação Espiritual. A propósito, foi a partir desse nome que o movimento de carismatização ficou mais conhecido, a saber, Movimento de Renovação Espiritual.

A tônica do movimento é primordialmente voltada para a necessidade do batismo do Espírito Santo como uma experiência distinta da salvífica e que seria capacitante para a vida evangelística e devocional dos fiéis da igreja com um todo. Para os adeptos do movimento, tal batismo era uma necessidade para combater o “esfriamento espiritual” que assolava as igrejas tradicionais que não possuiriam mais fervor. Os dons espirituais, glossolalia e demais manifestações advindas do fervor carismático seriam uma evidência de um "renovo". Deve-se destacar, todavia, que para este setor batista a ocorrência de glossolalia não seria a evidência por excelência para se saber se determinado indivíduo foi ou não batizado; outras evidências seriam capazes de comprovar tal batismo como o aumento do fervor espiritual.

Outro pastor que somou forças ao movimento de renovação, depois de José Rêgo e Rosalee, foi Enéas Tognini, que se tornou um dos maiores propagadores da renovação espiritual, seja através de seminários, seja através de extensa bibliografia produzida. 
A mensagem avivalista toma fôlego e os convites para preleções de Rosalee e José Rêgo se avolumam, mas um evento em especial será destacado pela relevância histórica de suas repercussões no rumo do setor da tradição batista no Brasil.

Durante os dias 11 a 18 de outubro de 1958, no ainda incipiente movimento carismático no protestantismo brasileiro, realizou-se a "Semana de Renovação", organizada pelo Grêmio do Seminário Teológico Batista do Sul do Brasil, no Rio de Janeiro, com o tema "O Pentecostes se repete?". Um dos preletores do evento foi justamente o pastor José Rêgo do Nascimento (XAVIER, 1997, p. 58-59).

Em uma sexta-feira, penúltimo dia do evento, o pastor José Rêgo recebeu um convite por parte de alguns seminaristas para participar de uma reunião de oração (vigília) na biblioteca do Seminário. José Rêgo, em carta ender eçada a Enéas Tognini (TOGNINI; ALMEIDA, 2007, p. 55-57), narra que cerca de 50 seminaristas oravam e cantavam até que, por volta da quarta oração "aconteceu pentecostes. O Espírito caiu sobre a casa, possuindo a muitos. Alguns seminaristas se deixaram cair no chão, outros por sobre as mesas, outros se levantaram e muitos confessavam pecados em voz alta, ouvindo-se gemidos e sons de choro incontido". As experiências narradas eram variadas, riso, choro, alguns pediam para que a experiência parasse por não mais suportarem e outros, pelo contrário, não queriam que ela cessasse.

As reações a este evento, bem como a própria existência do movimento, provocaram celeumas internas. Críticas contundentes ao movimento surgiram quase que imediatamente após os eventos ocorridos na biblioteca do Seminário Batista do Sul. Oficialmente, o Seminário se posiciona através de diferentes declarações. Uma delas fala de "ocorrências caracterizadas pelo extremado emocionalismo e excessos perturbadores [...] a necessidade de se distinguir entre a verdadeira espiritualidade e os excessos de emocionalismo, que são desvirtuamentos perigosos contra os quais devemos nos acautelar" (TOGNINI; ALMEIDA, 2007, p. 59). 
A partir desse momento a reação do setor tradicionalista (em contraposição ao setor renovacionista) começa a tomar ares mais incisivos a fim de manter sua unidade institucional, teológica e ideológica.

\section{A cisão batista}

O movimento de renovação pode ser dividido em dois momentos em razão de sua ênfase experiencial, embora seja difícil separá-las em termos cronológicos, a saber, um momento pré-renovacionista, com Rosalee, e um momento renovacionista propriamente dito com José Rêgo do Nascimento e Enéas Tognini (pode-se citar também a pessoa de Rosivaldo Araújo, pastor que compôs o hino oficial do movimento, chamado "Obra santa”). A ênfase primeira, de Rosalee, não se voltava para as experiências de êxtase, glossolalia e dons espirituais; estava mais direcionada a uma busca por uma vida devocional intimista de oração e pregação evangelística (o que em princípio não ia de encontro ao ethos batista de vida devocional e cúltica). Provavelmente foi por esse mesmo motivo que Rosalee não encontrou os empecilhos que José Rêgo e Enéas Tognini encontraram perante a instituição, já que quando o movimento já estava sob a chancela dos mesmos a disseminação das manifestações carismáticas se avolumou.

José Rêgo, Enéas Tognini e outros pastores e membros que aderiram ao movimento começaram a receber as reações institucionais, a começar pela reitoria do Seminário Teológico Batista do Sul (STBS). Em declaração publicada no Jornal Batista de 27 de outubro de 1958, a reitoria do STBS repudiou o ocorrido em sua biblioteca quando da vigília de seminaristas (conforme narrado acima), referindose ao evento como "extremado emocionalismo e excessos perturbadores, sobre os quais a Administração e os professores vêm sendo arguidos por terceiros. [...] são desvirtuamentos contra os quais devemos nos acautelar”.

Além de haver a beligerância institucional, a Igreja Batista da Lagoinha, que na época já começava a se destacar no movimento carismático protestante 
brasileiro, passa a ter que lidar com problemas internos (disputas entre membros acerca da legitimidade ou não do movimento e da experiência carismática nos moldes em que se propagava) e externos, já que foi alvo de pressão institucional. Durante assembleia da Convenção Batista Mineira realizada em Juiz de Fora, em julho de julho de 1961, a Igreja Batista da Lagoinha teve sua filiação cancelada sob alegação de desvirtuamento doutrinário.

No âmbito nacional, durante a quadragésima quarta Assembleia da Convenção Batista Brasileira - CBB, em 1962, formou-se uma comissão (que ficou conhecida como "Comissão dos Treze" em razão do número de seus componentes) para a análise da legitimidade do movimento de renovação e, mais ainda, para estudo do tema do Batismo no Espírito Santo à luz da tradição batista. A comissão deveria ser composta por três membros favoráveis à renovação espiritual e três contrários, sendo que os sete restantes deveriam ter a função de árbitros. Os membros desta comissão eram: Rubens Lopes, Werner Kaschel, J. Reis Pereira, Achilles Barbosa, Harald Schaly, David Gomes, José Rêgo do Nascimento, David Mein, João F. Soren, Delcyr S. Lima, Reynaldo Purim, Enéas Tognini e Thurmon Bryant (CBB, 1963, p. 9).

Um ano depois, na quadragésima quinta Assembleia da CBB realizada em Vitória, Espírito Santo, no dia 26 de janeiro de 1963, foi lido em plenário um parecer sobre a questão, do qual destacamos:

II) Verificamos que a expressão "batismo no Espírito Santo" nunca foi definida em declarações de fé publicadas pelos batistas através dos séculos e sobre seu significado as opiniões de teólogos e pensadores batistas são divergentes; mas também, reconhecemos:

1. Que a crença no batismo no Espírito Santo como uma "segunda bênção", ou seja, como segunda etapa na vida cristã, ou seja, ainda como uma nova experiência posterior à conversão não tem sido crença que caracterize os batistas brasileiros.

2. Que a prática do que ainda hoje chamam de "dom de línguas" e "dom de curas milagrosas" é igualmente estranha às crenças e práticas características dos batistas brasileiros.

3. Que o consenso geral dos batistas sobre a atuação do Espírito Santo na vida do crente é que ele se faz como um processo em toda a sua vida, processo esse que chamamos de "santificação progressiva", a qual depende da cooperação do próprio crente. 
4. Que qualquer experiência emotiva ou sensível de cunho pessoal que algum crente ou grupo de crentes tenha tido e que atribuem ao Espírito Santo, por mais genuína que seja para o indivíduo ou para o grupo, de modo nenhum pode constituir um exemplo ou um padrão a ser imitado por outros crentes, nem tampouco pode constituir base para doutrinamento dos outros ou para campanhas de avivamento.

III) Apraz-nos assinalar não haver divergência entre os batistas da Convenção Batista Brasileira nos pontos fundamentais da doutrina do Espírito Santo e que são os que constam da "Declaração de Fé das Igrejas Batistas do Brasil”.

IV) Achamos que se deve reafirmar o direito inerente a cada batista de se pronunciar livremente sobre a matéria, mas em linguagem cristã em que se perceba a preeminência do amor e o sincero desejo de um fortalecimento espiritual que se torna cada vez mais necessário em nossas igrejas e em nosso povo.

V) Mas achamos também que a ênfase dada a determinada interpretação da doutrina do batismo no Espírito Santo tem originado os seguintes abusos que, sinceramente, deploramos:

1. A realização de reuniões em que se notam os mesmos vícios próprios de reuniões pentecostais, isto é, a confusão no ambiente, a gritaria, os descontroles físicos, o falar em línguas e outros excessos de emocionalismo.

2. Uma atitude de orgulho espiritual que não quer admitir opiniões opostas e que classifica os que não experimentaram as mesmas emoções e experiências de carnais e mundanos.

3. Tentativas ostensivas ou veladas de proselitismo entre outras igrejas. VI) Achamos conveniente que esta Convenção advirta aos que porventura assim procedam que estão saindo da linha apostólica da ordem e da decência e que prejudicam com tal comportamento as relações entre as igrejas. (CBB, 1963, p. 14).

Este parecer foi aprovado por 477 votantes de um total de 488 presentes, sendo ainda decidido que aquelas igrejas que forem expulsas de suas respectivas convenções regionais o seriam também da nacional. Algumas igrejas foram retiradas do rol convencional e formaram posteriormente o que viria a ser a Convenção Batista Nacional que seria uma junção das igrejas adeptas do movimento de renovação espiritual.

\section{Considerações finais}

Por certo, trata-se de uma visão sumária das dinâmicas que permearam a formação da ala carismática no protestantismo brasileiro, notadamente no que concerne às igrejas batistas. 
Contudo, pode-se averiguar que esse processo de tensões e rupturas sofrido pela instituição batista nos revela aspectos interessantes acerca do homem com a experiência religiosa que poderiam ser destacados.

Existe sempre a busca por uma identidade com uma experiência primordial, originária, que nesse sentido seria a mais fundamental, mais pura e até mesmo arquetípica. O modelo no caso aqui narrado seria a experiência cristã primitiva da igreja no primeiro século.

Interessante notar que tanto aqueles que buscavam a renovação quanto aqueles que se pautavam pelo rigor doutrinário com a finalidade de manter a tradição estavam ao fim e ao cabo com a intenção de alcançar ou manter-se de acordo com tal experiência. Obviamente, as leituras eram divergentes, daí as tensões e rupturas nesse processo dialético de tradição/renovação.

Se por um lado os adeptos do movimento de renovação espiritual alegavam se apropriar da experiência originária através da vivência carismática, os que pugnavam pela tradição se diziam guardiões da mesma.

\section{REFERÊNCIAS}

ALVES, Rubem. Protestantismo e Repressão. São Paulo: Ática, 1979.

CAMPOS, Leonildo Silveira. Pentecostalismo e Protestantismo "Histórico" no Brasil: um século de conflitos, assimilação e mudanças. Horizonte, Belo Horizonte, v. 9, n. 22, p.504-533, jul./set. 2011.

CONVENÇÃO BATISTA BRASILEIRA - CBB. Parecer da Comissão dos Treze. Rio de Janeiro, 1963.

FRESTON, Paul. Breve história do pentecostalismo brasileiro. In ANTONIAZZI, Antonio; et al. Nem anjos nem demônios - Interpretações sociológicas do Pentecostalismo. 2. ed. Petrópolis: Vozes, 1994, 67-158.

MENDONÇA, José F. Curas Divinas ou Tendas das Curas Divinas. O Jornal Batista, quinta-feira, 22 de janeiro de 1959, Ano LIX, Rio de Janeiro, Num. 4, p. 4. 
MOREIRA, Thiago. Da tradição à renovação na Igreja Batista da Lagoinha: um olhar sobre o protestantismo renovado. 2016. Dissertação (Mestrado) - Programa de Pósgraduação em Ciência da Religião, Universidade Federal de Juiz de Fora, Juiz de Fora.

TOGNINI, Enéas; ALMEIDA, Silas Leite de. História dos Batistas Nacionais. Brasília: Lerban, 2007.

XAVIER, João Leitão dos Santos. Colunas da Renovação. Brasília: Lerban, 1997. 